\title{
Application of Willingness-to-Pay Methods to Value Transport Externalities in Less Developed Countries
}

\author{
J de D Ortúzar ${ }^{1}$, L A Cifuentes ${ }^{2}$ and H C W L Williams ${ }^{3}$
}

Environment and Planning A 32: 2007-2018. 2000.

\begin{abstract}
In this paper we report on two applications of the Willingness-to-Pay (WTP) approach to valuing transport externalities in Santiago, Chile. The first involves a contingent valuation study of mortality risk due in part to pollution-related causes, and the second, a stated preference study for valuing the reduction of risk from road fatalities. It is concluded that the approaches, and particularly that based on stated choice methods, offer practical and consistent methods of establishing unit values in higher income developing countries. The unit values derived from the WTP methods appear to justify a greater allocation of resources to safety and pollution countermeasures compared with those derived from more traditional approaches.
\end{abstract}

1. Department of Transport Engineering, Pontificia Universidad Católica de Chile, Santiago, Chile Email: jos@ing.puc.cl

2. Department of Industrial and Systems Engineering, Pontificia Universidad Católica de Chile, Santiago, Chile; Email: lac@ing.puc.cl

3. Department of City and Regional Planning, Cardiff University, Cardiff, UK.

Email: williamsh@cardiff.ac.uk 


\section{Introduction}

In many countries of the developed world, various methods have been used for valuing the external effects of road traffic and, in particular, congestion, pollution, noise, visual intrusion and amenity loss. An extensive range of applications has been reported by, among others, Quinet (1994, 1997), Maddison et al (1996), Green et al (1997) and ECMT (1998) where international comparisons are documented. The taxonomy and characteristics of the valuation methods, together with the relative strengths and weaknesses of the different approaches, are widely treated in the above literature and will not be reviewed here. The main thrust of this research is the establishment of the full social costs of road transport as a basis for efficient pricing in the transport sector and extending the scope of social cost benefit analysis for improved decision making in project appraisal.

Although valuation techniques and cost benefit analysis are increasingly applied to environmental problems in less developed countries (see, for example, Abelson, 1996 and Georgiou et al, 1997), with the rare exception of congestion and accident costing, the valuation of transport externalities in less developed countries (LDCs) is in its infancy. One approach which could be considered - and not infrequently applied in practice - is the transfer of US or European unit values to developing countries, with suitable adjustment for relative income levels. However, it is known from measurements of the Value-of-Time that transferability to different cultural settings may be suspect and justifies the implementation of local studies.

In several developed countries Willingness-to-Pay (WTP) has become an institutionally accepted means for deriving monetary values from revealed and expressed preference studies. This approach is not however represented among the methods currently applied in the transport sector of the less developed world. Due to widespread market failure which detracts from the application of revealed preference methods and the practicalities of eliciting responses to relatively complex surveys in developing countries, the WTP approach has usually been considered inappropriate.

The main aim of the present paper is to consider the potential for extending the scope and quality of valuation methods at least for higher income developing countries, where there is a large potential for traffic growth and where road accidents and pollution derived from traffic are already severe. The paper reports on two studies in which willingness-to-pay (contingent valuation and stated preference) methods ${ }^{1}$ have been applied to accident and pollution costing in Santiago, Chile. These are among the first applications of expressed preference methods to address the costing of transport externalities in less developed countries and, to the authors' knowledge, the first of the stated preference approach. As we shall describe, both applications draw on state-of-the-art developments in international research.

It is apparent that Chile exhibits a number of features of both developed and developing market economies. It does not have a very highly skewed population age structure, characteristic of many low-income developing countries, nor does it suffer from severe unemployment (the unemployment rate, under a recent heavy recession, was under $10 \%$ ). Car ownership in its capital, Santiago, is currently at 0.15 per head, and car use has been growing rapidly at $6 \%$ per annum. The primary network outside the capital is still

\footnotetext{
${ }^{1}$ There is potential confusion in reference to SP, which is sometimes used synonymously with all Expressed Preference methods. As described here (and in the transportation literature), the SP technique, also sometimes referred to as Conjoint Analysis, involves the construction of hypothetical choice contexts in which individuals are asked to select (definite choice), rate or rank alternatives. The information derived from the experiment is then analysed using, typically, logit or probit models (see Ortuzar and Willumsen, 1994).
} 
under development and the scope for infrastructure investment is considerable. In these regards Chile is typical of a developing market economy and rather similar to a range of other Latin American Countries, such as Argentina, Columbia and Venezuela. In common with many other middle income countries, road traffic accidents and pollution are very significant problems. Indeed, the climate, geographical disposition and topography of Santiago make it susceptible to the build up and local concentration of pollutants. In the winter months of May to July the concentration of particulate matter is among the highest in the world with well-documented health effects (Ostro et al, 1996; Cifuentes et al, 1999b).

Although there are pockets of relative poverty in the capital, Santiago is a sophisticated city, with mature institutions, good educational infrastructure, and technically competent public servants who have long experience of social cost benefit analysis in project appraisal. As a higher income developing country that has successfully implemented and officially supported value-of-time research it therefore appeared that Chile would be an appropriate country for testing further applications of willingness-to-pay methods.

As a prelude to a discussion of the two applications, the current use of monetary values in accident and pollution costing in Chile is considered. These current numerical values will provide an important contrast to those derived from WTP, a point to which we shall return in a concluding section.

\section{Use of Monetary Values for Accident and Pollution Costing in Chile}

For the purpose of accident costing, the human capital (HC) approach is widely applied in developing countries (Hills and Jones-Lee, 1983; Jacobs, 1995; Jacobs and Aeron-Thomas, 1999). There are no examples of local WTP approaches, which are increasingly accepted for both fatal and non-fatal accident costing in developed countries. For Chile, using the human capital approach, the gross output value of a statistical life amounted to US\$ 42,000 at 1989 income figures (Eskeland, 1994). This value was recently updated by $45 \%$ (the increase in per capita income from 1989 to 1997) to $\$ 60,900$ in a study done for the National Environmental Commission (Cifuentes, 1998). Such costs are used to assess the scale of accident fatalities in the country and as an aid to resource allocation to accident counter-measures ${ }^{2}$. Accident costs are however seldom applied in investment appraisal in Chile, the difficulty of their estimation over the lifetime of a project being a contributing factor.

Pollution costing studies have been undertaken in several countries of the developing world, including: Indonesia, Taiwan, Thailand, India, China, Central and Eastern Europe, Brazil and Chile (see Georgiou et al, 1997, section 6.7; and Ostro, 1996). In the case of air pollution, in which adverse health effects have their origin in both the industrial and transportation sectors, damage estimates are usually obtained from doseresponse functions applied in conjunction with unit values. The latter are either local (often human capital) values or derived from a developed country setting according to income ratios adjusted for the income elasticity of demand.

Santiago is one of the few cities of the developing world where damage estimates of pollution costs have been made. Here, local epidemiological evidence is available to

\footnotetext{
${ }^{2}$ In 1998 there were 1,850 fatalities on the spot, including 877 victims in urban areas, in a country with only 14 million people and some two million cars. The situation is improving under the initiatives of a newly created National Agency for Road Safety (NARS). In one such initiative, the Concessions Division of the Ministry of Public Works incorporated a road safety prize in its call for tenders to private companies interested in building and operating private toll roads. Each death averted, over a base figure calculated after the first year of operation of the new facility, is assessed at the gross output value of a statistical life. $50 \%$ of the proceeds are granted to the concessionaire in the form of a raised toll for the following year, based on the notion that an enhanced service is being offered..
} 
establish dose-response functions (see Ostro et al, 1996 and Cifuentes et al, 1999b). A study undertaken for the National Environmental Commission (Sanchez and Valdez, 1997) estimated the social benefits of Santiago's Decontamination Plan using the damage function approach, as recommended by Ostro (1996), and values derived from the human capital method. The net present value of the Plan (designed to comply with the primary $\mathrm{PM}_{10}$ standard in 15 years) was US\$ 392 million. A more recent study (Cifuentes, 1998) used lower bound WTP values transferred from the USA to estimate the value of health related effects due to air pollution levels in Santiago. Using these values, the social benefits for the same concentration reductions amounted to US\$2,077 million. The wide discrepancy between the human capital and transferred WTP values emphasises the crucial importance of deriving local estimates of the latter.

\section{A Contingent Valuation Study of Pollution Related Mortality Risks}

The research reported here involves a determination of the willingness-to-pay for small reductions in the risk of death at two stages: the current age and an advanced age, the latter values being associated with air pollution which mainly affects the elderly (Wilson and Spengler, 1996). Thus, when valuing improvements to current exposure that would reduce future risks, it is important to know how much people would be willing to pay today for policies which give rise to such improvements in the future.

The four-part survey instrument used was based on the work of Krupnick et al (1999). Its main objective was to obtain the WTP for present and future risk reductions, while trying to overcome some problems found in previous CV studies - mainly that some respondents fail to understand the basic notion of probability, attributing similar WTP to different reductions of risk, and that respondents may give zero WTP to reduce future risks of death due to lack of understanding of the commodity being valued. The approach differs from previous CV studies of risk reductions in the following ways: (i) the timing of risk reductions and the attention given to the timing of payment; (ii) the proposal of a base-line risk accepted by respondents as their own, according to their age and gender, and the fact that there is no mention in the questionnaire about the policy under which the risk reduction was to be achieved.

The four parts of the questionnaire are composed as follows. The objective of the first is to familiarise respondents with the concept of risk of death and with its perception. In addition, it draws attention to the main causes of death in Chile, by age and gender, and about common measures for mitigating these causes of death and their costs. The objectives of the second part are to introduce an age and gender specific baseline risk, to check if respondents accept it as their own risk, and then to obtain WTP for reductions in the risk of death in the next ten years of life. Proposed reductions in baseline risk are one in a thousand and five in a thousand. The results which are reported here used an open-ended payment elicitation method. The baseline and the reductions in risk were presented graphically, using a matrix of 1,000 circles; respondents were presented with the baseline risk, and were asked to rub-out the risk reductions being valued. This method appeared to work well and suggested that the surveyed individuals had acquired a good understanding of the questions asked.

The objective of the third part is to obtain WTP for the reduction in the risk of death between 70 and 80 years of age, once the person has reached 70. That is, for averting premature deaths such as those normally associated with pollution effects (Schwartz, 1994). The same approach as in part two is used, but only the reduction of five in one thousand is presented. Finally, the objective of the last part of the questionnaire is to obtain detailed socio-economic data in order to aid stratification in model estimation. 
After establishing the base line risk and having it accepted by the respondent, the fundamental questions in the second part of the questionnaire took the following form.

The measures needed to achieve a reduction in premature deaths in the next decade involve certain costs as we saw earlier in the questionnaire. Taking these into account please answer the following questions:

- How much money would you be willing to pay monthly for the next ten years in order to decrease your own possibility of dying by one in one thousand?

Chilean $\$$ month ................ Nothing (why?)

- How much money would you be willing to pay monthly for the next ten years in order to decrease your own possibility of dying by five in one thousand?

Chilean \$/month ................ Nothing (why?)

- How certain are you that you would pay that amount and not another?

a) very sure ........... b) reasonably certain .......... c) not very sure

In the third part, respondents were first informed that the average life expectancy of Chilean males and females in 1992 was 71 and 77 years of age, respectively. Then they were asked whether they believed they would reach the age of 70 and, if so, to consider their attitude towards payment now to reduce the risk of dying between the ages of 70 and 80 . They were informed of the (large) probability of dying in this interval, and then asked the following:

Imagine that on the basis of certain measures taken by the government in this year it is possible to reduce the probability that you would die between 70 and 80 , once you reach 70, by five in one thousand (i.e. from 410 in 1000 to 405 in 1000), then:

- How much money would you be willing to pay monthly for the next ten years, in order to have these measures taken?

Chilean \$ / month

Nothing (why?)

- Recall that there is a possibility that you will not survive until 70 in which case your payment today would be useless. Please review your answer and, if you want to correct it, put the new value in the space below. If not, pass to the next question

Chilean \$ / month

- How certain are you that you would pay that amount and not another?

a) very sure

b) reasonably certain

c) not very sure

It is interesting to note that people tend to associate the phrase "government measures taken in this year to avoid premature deaths in the future", with pollution reduction measures because these are much in vogue in Santiago, and repeatedly being discussed and criticised as ineffective in the press.

The socio-economic data collected included: age, gender, civil status, education level, activity/profession, number of family members and income level.

Results

We summarise here the findings from a sample of 94 individuals taken from the Campus San Joaquín of the Pontificia Universidad Católica de Chile. Further details are available in Cifuentes et al (1999a). The age and gender distribution of this sample is shown in Table 1.

TABLE 1 ABOUT HERE

Firstly, it is interesting to mention that the survey form took approximately 30 minutes to complete with an interviewer. A significant part of this time was spent familiarizing the respondent with the concept of probability and baseline risk using the matrix of circles. Secondly, $41 \%$ of respondents had experienced the death of a relative in the last two years. Also, 65\% accepted the base-line risk (27\% thought it should be higher 
and only $8 \%$ considered that it should be lower).

Risk reductions of 5/1000 were indeed found to be valued higher than reductions of $1 / 1000$. Tests were made for external validity by asking separate groups these questions in a different order and noted consistent results, with higher WTP given for the greater risk reduction. Also, the WTP values for respondents with recent death of a relative were higher than the rest (a reasonable result). Finally, although WTP values were highly dispersed, only $25 \%$ of respondents reported a WTP of zero.

In terms of reaching an advanced age, $55 \%$ of respondents believed they would reach 70, 9\% thought they would not, and the remainder (36\%) did not know. Respondents appeared surprised with the information about the number of deaths between 70 and 80 years of age. Finally, $76 \%$ of respondents found it reasonable to pay today for the implementation of government measures which would be beneficial only at 70 . Surprisingly, the five individuals who believed they would not reach 70 expressed a nonzero willingness-to-pay (perhaps reflecting their anticipation of benefits from a policy implemented before their demise).

Table 2 presents estimates of the value of a statistical life calculated as the ratio between the net present value of the willingness-to-pay and the risk reduction under consideration (a 5\% annual discount rate was used but, given the payment schedule of ten years, results are not particularly sensitive to it).

TABLE 2 ABOUT HERE

Although the results are based on data for a sample of 94 individuals which is not entirely representative of the population in Santiago, two important conclusions can be derived. Firstly, the ratio of willingness-to-pay for risk reductions of 5/1000 and 1/1000 is close to four and this is consistent with expectations given the decreasing marginal utility of risk reductions. It also suggests that people are capable of distinguishing between rather small reductions in risk. Secondly, the value for a statistical life is close to five times higher than that obtained from the human capital approach. This is consistent with findings elsewhere (see, for example, Cropper and Freeman, 1991). We return to consider the implications of these results in the final section.

\section{An Application of Stated Preference in the Valuation of Road Fatality Risks}

\section{Design of the Stated Preference Experiment}

To explore how much people were prepared to pay for the reduction in the risk of death from a road accident, we chose a quasi-market involving route choice for drivers. Specifically, the inter-urban journey between Santiago and Valparaíso (Chile's main port some $120 \mathrm{~km}$ to the east) was selected and respondents were invited to choose between two alternative states of the highway, R1 and R2, on the basis of three attributes: travel time (in hours), accident risk (to be defined) and toll charge, all other things being equal.

The choices made by each individual, together with the values of each attribute in each choice situation, were the data used in the estimation of the following binary logit discrete choice model. Here, the probability $\mathrm{P}_{\mathrm{i}}$ of selecting the "low risk" (LR) and "high risk" (HR) options (in each situation the risk of having a fatal accident was different by design) is expressed in terms of the representative utilities $V_{i}$

$P_{i}=\frac{\exp \left\{V_{i}\right\}}{\exp \left\{V_{L R}\right\}+\exp \left\{V_{H R}\right\}}, \quad i=L R, H R$.

$\mathrm{V}_{\mathrm{i}}$ is given by the linear expression (see, for example, Ortuzar and Willumsen, 1994) 
$V_{i}=\theta_{T}$ Toll $_{i}+\theta_{A}$ Accident Risk $_{i}+\theta_{t}$ Time $_{i}$

with the vector of parameters $\boldsymbol{\theta}$ estimated by maximum liklihood.

The measurement of accident risk does, of course, present a particular challenge because, even in Chile, the risk of dying in a road accident is extremely low in percentage terms. We experimented with several forms to treat this problem (see Rizzi et al, 1999 for full details) and concluded that the preferred one was through a variable defined as the number of car accidents per year in which at least one of the occupants died. Table 3 shows a specimen "card" of the experiment.

TABLE 3 ABOUT HERE

We assessed the importance of including questions (see below) about road safety and accident experience, prior to or after the SP questionnaire, and also that of mentioning that the objective of the survey was to estimate the value of life in the letter introducing the SP experiment.

The factorial design used was the traditional one based on differences of the aforementioned generic attributes. In this case three levels were considered for each attribute, as shown in Table 4.

TABLE 4 ABOUT HERE

Consistent with current good practice, simulation was used to check that the design was well balanced and allowed for good parameter recovery (see Pearmain et al, 1991; Ortúzar and Willumsen, 1994).

The survey instrument involved a self-completion questionnaire in three parts. The first part includes questions relating to the respondent's driving characteristics and, in particular:

- highway driving experience and familiarity with the Santiago-Valparaíso highway

- previous accidents experienced by driver or acquaintances and safety characteristics of the car (a third of the sample had this question after the SP questionnaire).

It is important to remark that the selected highway is probably the most important and well-known road in the country and traffic conditions, particularly in long weekends or holiday periods, are a constant subject of news programmes. It was made clear to respondents that the two options in each hypothetical situation referred to the same actual highway, with only the toll, travel time and accident rates subject to variation.

The second component of the questionnaire is the SP exercise itself, with nine choice situations as discussed above. After finishing it, further questions were asked to gauge the perceived reality of the exercise. The final part sought the usual socio-economic data, including: education level, marital status, number of children, income, etc., to be used eventually in model estimation.

The survey was sent to both academic and non-academic staff of several Faculties of the Pontificia Universidad Católica de Chile and of the Faculty of Engineering at the Universidad de Chile. In all 121 completed forms were returned (response rate greater than $40 \%$ ) of which 118 were judged appropriate for further analysis (the other three declared not to have driven on a highway in the last year); furthermore, 102 of these have driven at least once on the Santiago-Valparaíso highway in the last year. The gender and age distribution of this estimation sample is shown in Table 5; as can be seen the majority are males and in their prime.

TABLE 5 ABOUT HERE

The data may be stratified by income level, education level, married status, number and age of children, and by those who had had or were acquainted with people involved in a serious accident in the past two years. With regard to the latter, it is interesting to note that, while 
only 11 had been involved in a serious accident themselves, 41 (34.7\%) had a relative or acquaintance who had died in a road accident in the last two years.

Before the discrete choice analysis, the data were screened for departures from linear compensatory behaviour by individuals (i.e. that assumed in our discrete choice logit specification) or for the existence (or appearance) of consistent lexicographic behaviour ${ }^{3}$ and consistent non-linear compensatory behaviour ${ }^{4}$ (see Rizzi et al, 1999 and Saelesminde, 1999).

\section{Results}

Linear logit models were estimated for various stratifications of the sample. In particular we tested the effects of removing those exhibiting lexicographic behaviour and those with answers that were inconsistent with linear compensatory behaviour. Among the strata tested were the following:

- Case 1: all responses (i.e. 1,033 observations)

- Case 2: as above but excluding subjects exhibiting apparent lexicographic behaviour (706 observations left)

- Case 3: as above but excluding subjects who showed any inconsistent responses with compensatory linear behaviour or who did not find the exercise realistic (289 observations left)

- Case 4: as above but including all the consistent responses of subjects removed in the previous step (584 observations in total). This is the only case where individual responses of subjects are considered.

The results are shown in Table 6 which presents the parameters for the toll, risk of accident variable and travel time, and the ratios of the last two to the first, which can be interpreted as WTP for risk reduction and value of time, respectively (see Gaudry et al, 1989). It is important to mention that we tested for framing and other effects using the various cases tested (i.e. using frequency rather than number of accidents, and including the questions about safety and involvement in road accidents prior to or after the SP questionnaire). We used structural parameters for mixing data from the different cases, but found that results were not very sensitive to them (see Rizzi et al, 1999). As can be seen, the results are most sensitive to the elimination of those participants who exhibited lexicographic behaviour ${ }^{5}$.

TABLE 6 ABOUT HERE

Several points are worth noting. Firstly, once the individuals exhibiting lexicographic behaviour are removed, the point estimates of both value-of-time and accident valuation are remarkably robust with respect to model stratum (in fact, as the confidence intervals are almost identical these values are clearly not statistically different at the $95 \%$ level); however, the estimates for Cases 2, 3, and 4 are significantly lower than those corresponding to the first stratum, Case 1. Secondly, the values of time are in close agreement with previous Chilean values derived from route and mode choice models estimated with both SP and RP data (see, for example, Ortúzar, 1999). This is very gratifying and seems to imply that the experiment was both well designed and well understood by the respondents.

Finally, it is clear that the confidence intervals for the point estimates in case 3 and, especially, case 4 are narrower than the rest. This was expected as these cases only consider responses which are consistent with compensatory linear behaviour.

\footnotetext{
${ }^{3}$ That is, did not exhibit compensatory behaviour but chose according to a single attribute.

${ }^{4}$ For example, individuals who have non-linear terms in an otherwise linear-in-parameters utility function.

${ }^{5}$ Of the 37 individuals detected, 20 were lexicographic on the accident variable, 13 on travel time and only four on the toll charge.
} 
In order to obtain the value of a statistical life in the case of road fatalities, an aggregation over the annual flow along the highway must be made. Special attention must be paid to the individuals exhibiting lexicographic behaviour; even if they are not truly lexicographic (i.e. they have a value of safety so high that they are not able to compromise given the toll values in the experiment), it is clear that their willingness-to-pay is significantly higher than those derived in Table 6. So, in any case, the WTP values derived from models 2-4 can be labelled as conservative. On the other hand, the WTP values in the table are those of the drivers and not of all individuals (the average number of car occupants that died per accident in 1996 and 1997 was 1.32 persons per vehicle, see Rizzi et al, 1999).

From the annual flow on the Santiago-Valparaíso route $(3.7$ million cars in both directions), the road fatality rates along the route, and the WTP for a reduction in risk of a fatal accident (derived from case 4 which is the best model in Table 6) it is straightforward to estimate the value of a statistical life as approximately US\$ 521,360; its confidence interval, derived from the corresponding WTP confidence interval for case 4, is [US\$ 392,420 - 672,730]. Note that even if we had taken the lowest WTP value in Table 6 (the lower confidence limit for Case 3) we would have obtained the conservative value US\$ 308,500 .

Within the context of the present experiment, these values are also conservative because there is no consideration for: public transport users, provision for altruistic behaviour (see Freeman, 1993), or pedestrians circulating in areas of conflict with the highway; nor do they take into account additional costs such as traffic disruptions, police costs and hospital care, etc. However, even the lower bound value of US\$ 308,500 is considerably higher than the 1997 human capital figure of US\$60,900.

\section{Discussion and Conclusion}

In higher income developing countries, of which Chile is an example, there will be several contexts in which the limitations underpinning WTP methods are not significantly different from those in developed countries, and preferences, revealed or expressed, could be a useful guide to policy formulation and appraisal.

The expressed preference experiments reported here are based on state-of-the-art designs. Both the stated preference and the contingent valuation applications appear to have produced consistent and reasonable numerical results. No major problems are anticipated in extending these methods to larger samples or applying the approaches to similar higher income developing countries. Past experience in discrete choice modelling and value-oftime studies supports this view (Ortúzar and Willumsen, 1994).

It should be emphasised that the values attributed to risk reductions derived from the two experiments are not directly comparable as the CV study is measuring the WTP to reduce the risk of dying from a number of different causes, including those from pollutionrelated causes, at some time in the future. The SP experiment identifies a single cause of death at the present time 6 . However, even allowing for the propensity for expressed preference approaches to generate high values compared with other methods (see, for example, the discussion in Quinet, 1994; and Randall and Hoehn, 1996), the studies reported in this paper strongly suggest that the value of a statistical life derived from willingness-to-pay approaches is significantly higher than that currently accepted from more traditional human capital analyses. In this respect, our findings are entirely consistent with

\footnotetext{
${ }^{6}$ Empirical evidence from developed countries suggests that WTP for reductions in involuntary, poorly understood and uncontrollable risks, such as those associated with air pollution, can exceed that of largely voluntary, well understood and easy to control risks such as those associated with road accidents by a factor of two or three (Department of Health, 1999).
} 
the numerical values obtained from the HC approach and range of WTP estimates in developed countries. We are aware, from the experience in developed countries, that there are many factors which will influence the introduction or extension of the use of monetary values as the basis for transport policy formulation and decision making. We would include here: the institutional context within which transport decisions are made and projects are financed; existing frameworks for analysis and evaluation; and the ease with which information can be acquired. Additionally, the acceptance of the WTP approach, is likely to depend on the extent to which the numerical values produced are consistent with any currently accepted values. Much higher numerical values may meet with institutional resistance, particularly by treasury officials - an experience familiar in the developed world. The authors were informed by one senior official that this would almost certainly be the case in Chile.

However, insofar as willingness-to-pay is accepted as a suitable social welfare measure in less developed countries, the failure to implement appropriate evaluation methods may well have significant consequences. We draw the following conclusions from the large differences between the human capital and willingness-to-pay values. Firstly, it suggests that an increase of resources for accident and pollution counter-measures may well be justified on both social efficiency and environmental grounds. Secondly, it is also probable that in investment appraisals, where social cost benefit analysis is still not widely applied in practice, inappropriate decisions are being taken both on resource allocation between modes and in respect to projects and programmes involving large capital sums.

\section{Acknowledgements}

We wish to acknowledge the helpful comments of the anonymous referees on a prior version of this paper. We also wish to thank our research students Jorge Escobari and Jose Joaquin Prieto, who implemented the CV part of the work, and particularly Luis Ignacio Rizzi who implemented the SP work on road accidents and was instrumental in interpreting its results. Finally, we are very grateful to FONDECYT for its financial support through project 1970117, to Fundación Andes, to the Research and Graduate Division of the Pontificia Universidad Católica de Chile (DIUC) and to the British Environment and Physical Sciences Research Council (EPSRC) for having financed a sabbatical stay of the first author in London where this paper was conceived.

\section{References}

Abelson P (1996) Project Appraisal and Valuation Methods for the Environment with Special Reference to Developing Countries. Mac Millan, New York.

Cifuentes LA (1998) Antecedentes para Revisión de Normas de Calidad del Aire en la Resolución $N^{\circ} 1215$ del Ministerio de Salud, 1978. Anexo VI: Evaluación Económica de los Beneficios Sociales. CONAMA Contrato No 07-002-043, Santiago (in Spanish).

Cifuentes LA, Prieto JJ and Escobari J (1999a) Valuing mortality risk reductions at present and at an advanced age: preliminary contingent valuation results in Chile. XVII Latin American Meeting of the Econometric Society. Cancun, Mexico. August 1999.

Cifuentes LA, Vega J and Lave L (1999b) Daily mortality by cause and socio-economic status in Santiago, Chile. Epidemiology Supplement 10, S45. 
Cropper ML and Freeman AM (1991) Environmental health effects. In JB Braden and CD Kolstad (eds.), Measuring the Demand for Environmental Quality. North Holland, Amsterdam.

Department of Health (1999) Economic Appraisal of the Health Effects of Air Pollution. Ad Hoc Group on Economic Appraisal of the Health Effects of Air Pollution. HMSO, London.

ECMT (1998) Efficient Transport for Europe: Policies for Internalisation of External Costs. European Conference of Ministers of Transport, Paris.

Eskeland GS (1994) The costs and benefits of an air pollution control strategy for Santiago, Chile. In Chile: Managing Environmental Problems: Economic Analysis of Selected Issues. Report No. 13061-CH, Environmental and Urban Development Division, Latin American and Caribbean Region, World Bank, Washington, D.C.

Freeman AM (1993) The Measurement of Environmental and Resource Values: Theory and Methods. Resources for the Future, Washington D.C.

Gaudry MJI, Jara-Díaz SR and Ortúzar J de D (1989) Value of time sensitivity to model specification. Transportation Research 23B, 151-158.

Georgiou S, Whittington D, Pearce D and Moran D (1997) Economic Values and the Environment in the Developing World. Edward Elgar, Cheltenham.

Greene DL, Jones DW and Delucchi MA (Eds.) (1997) The Full Costs and Benefits of Transportation. Springer-Verlag, Berlin.

Hills PJ and Jones-Lee MW (1983) The costs of traffic accidents and the valuation of accident prevention in developing countries. (A Report to the World Bank) also in summarised form as Chapter 23 in Highway Investment in Developing Countries. Thomas Telford, London. 189-196.

Jacobs GD (1995) Costing road accidents in developing countries. Overseas Road Note 10, Transport Research Laboratory, Crowthorne.

Jacobs GD and Aeron-Thomas A (1999) A review of global road accident fatalities. In TRL Annual Research Review 1999, Transport Research Laboratory, Crowthorne.

Krupnick AJ, Alberini A, Cropper M, Simon N, Itaoka K and Akai M (1999). Mortality risk valuation for environmental policy. Discussion Paper 99-47, Resources for the Future, Washington, DC.

Maddison D, Pearce D, Johansson O, Calthrop E, Litman T and Verhoef E (1996) The True Cost of Road Transport. Earthscan Publications, London.

Miller T R (2000) Variations between countries in values of statistical life. Journal of Transport Economics and Policy 34 (2), 169-188.

Ortúzar J de D (1999) South American Value of Time Research. In HF Gunn (ed.), The Value of Time. PTRC Education and Research Services Ltd., London (in press).

Ortúzar J de D and Armstrong PM (1995) Confidence intervals and the social value of travel time savings. Proceeding $23^{\text {rd }}$ European Transport Forum, Vol P393: Models and 
Applications. PTRC Education and Research Services Ltd., London.

Ortúzar J de D and Willumsen LG (1994) Modelling Transport. Second Edition, John Wiley and Sons, Chichester.

Ostro B (1996) A Methodology for Estimating Air Pollution Health Effects. WHO/EHG/96.5, Office of Global and Integrated Health, World Health Organisation, Geneva.

Ostro B, Sanchez JM, Aranda, C and Eskeland GS (1996) Air pollution and mortality: results from a study in Santiago, Chile. Journal of Exposure Analysis and Environmental Epidemiology 6, 97-114.

Pearmain D, Swanson J, Kroes E and Bradley M (1991) Stated preference techniques: a guide to practice. Steer Davies Gleave and Hague Consulting Group, London.

Quinet E (1994) The social cost of transport: evaluation and links with internalisation policies. Chapter 2 in Internalising the Social Costs of Transport. Organisation for Economic Cooperation and Development, Paris.

Quinet E (1997) Full social cost of transportation in Europe. In D L Greene, DW Jones and MA Delucchi (Eds) The Full Costs and Benefits of Transportation. Springer-Verlag, Berlin.

Randall A and Hoehn JP (1996) Embedding in market demand systems. Journal of Environmental Economics and Management, 30, 369-380.

Rizzi LI, Garrido RA, Ivelic AM and Ortúzar J de D (1999) Valor social de la seguridad en carreteras: un enfoque basado en el comportamiento. Working Paper 69, Department of Transport Engineering, Pontificia Universidad Catolica de Chile (in Spanish).

Saelensminde K (1999) Stated choice valuation of urban traffic air pollution and noise. Transportation Research 4D, 13-27.

Sanchez JM and Valdes S (1997) Estimación de los Beneficios del Plan de Prevención y Descontaminación de la Región Metropolitana. Informe preparado para la Comisión Nacional del Medio Ambiente, Universidad de Chile, Santiago (in Spanish).

Schwartz J (1994) Air pollution and daily mortality: a review and meta analysis. Environmental Research 64, 36-52.

Wilson R and Spengler J (eds.) (1996) Particles in Our Air: Concentrations and Health Effects. Harvard University Press, Cambridge, MA. 


\begin{tabular}{|l|c|c|}
\hline Age/Gender & Male & Female \\
\hline \hline Less than 30 years old & 25 & 11 \\
\hline Between 30 and 49 years & 20 & 23 \\
\hline Between 50 and 65 & 10 & 5 \\
\hline \hline Total & 55 & 39 \\
\hline
\end{tabular}

Table 1: Age and gender distribution of the CV sample

\begin{tabular}{|l|c|c|c|}
\hline Risk Reduction & $\begin{array}{c}\text { Median } \\
\text { WTP }(\mathbf{U S \$ )}\end{array}$ & $\begin{array}{c}\text { Net Present } \\
\text { Value of WTP } \\
\text { (US\$) }\end{array}$ & $\begin{array}{c}\text { Implicit Value of } \\
\text { Statistical Life } \\
\text { (US\$) }\end{array}$ \\
\hline 1 in 1000 & 3.0 per month & 285.1 & 285,113 \\
\hline 5 in 1000 & 12.0 per month & $1,127.0$ & 225,400 \\
\hline $\begin{array}{l}5 \text { in } 1000 \text {, between } 70 \\
\text { and } 80 \text { years of age }\end{array}$ & 1.3 per month & 128.2 & 25,632 \\
\hline
\end{tabular}

Table 2: Estimates of the implicit value of a statistical life for CV experiment

\begin{tabular}{|lcc|}
\hline Attribute & Route R1 & Route R2 \\
\hline \hline Toll (US\$) & 6.0 & 7.0 \\
Car accidents with deaths per & 10 & 22 \\
year & & $2: 15$ \\
Travel time (hours) & & $1: 45$ \\
\hline
\end{tabular}

Table 3: Specimen Card in the SP Experiment

\begin{tabular}{|c|c|c|c|c|c|c|}
\hline Case & \multicolumn{3}{|c|}{ Route R1 } & \multicolumn{3}{c|}{ Route R2 } \\
\hline & Time (hrs) & Accidents & Toll (US\$) & Time (hrs) & Accidents & Toll (US\$) \\
\hline 1 & $1: 30$ & 21 & 6.0 & $2: 00$ & 12 & 5.0 \\
\hline 2 & $2: 30$ & 8 & 6.0 & $1: 45$ & 17 & 5.0 \\
\hline 3 & $1: 30$ & 8 & 7.0 & $2: 00$ & 17 & 5.0 \\
\hline 4 & $2: 30$ & 21 & 4.0 & $1: 45$ & 12 & 7.0 \\
\hline 5 & $2: 15$ & 12 & 6.0 & $2: 30$ & 17 & 5.0 \\
\hline 6 & $1: 30$ & 12 & 7.0 & $2: 00$ & 17 & 4.0 \\
\hline 7 & $2: 15$ & 8 & 7.0 & $2: 30$ & 17 & 4.0 \\
\hline 8 & $2: 30$ & 12 & 5.0 & $1: 45$ & 17 & 7.0 \\
\hline 9 & $2: 15$ & 21 & 5.0 & $2: 30$ & 12 & 7.0 \\
\hline
\end{tabular}

Table 4: SP design 


\begin{tabular}{|l|c|c|}
\hline Age/Gender & Male & Female \\
\hline Less than 30 years old & 14 & 12 \\
\hline Between 30 and 49 years & 49 & 26 \\
\hline Between 50 and 65 & 10 & 5 \\
\hline Older than 65 & 2 & - \\
\hline Total & 75 & 43 \\
\hline
\end{tabular}

Table 5: Age and gender distribution in SP sample

\begin{tabular}{|l|c|c|c|c|}
\hline Parameter (t-ratio) & Case 1 & Case 2 & Case 3 & Case 4 \\
\hline \hline Toll (US\$) & -0.641 & -1.157 & -0.900 & -0.954 \\
& $(-5.3)$ & $(-4.7)$ & $(-5.6)$ & $(-8.5)$ \\
\hline Accidents & -0.198 & -0.218 & -0.156 & -0.177 \\
& $(-6.3)$ & $(-5.0)$ & $(-5.2)$ & $(-4.2)$ \\
\hline Time (hrs) & -3.405 & -5.113 & -3.628 & -3.551 \\
& $(-5.9)$ & $(-4.9)$ & $(-6.7)$ & $(-9.5)$ \\
\hline WTP accidents (US\$/acc.) & 0.309 & 0.188 & 0.173 & 0.186 \\
[confidence interval $\left.^{(\mathrm{a})}\right]$ & {$[0.21-0.47]$} & {$[0.12-0.30]$} & {$[0.11-0.26]$} & {$[0.14-0.24]$} \\
\hline Value of Time (US\$/hr) $\left.^{\text {[confidence interval }}{ }^{(\mathbf{a})}\right]$ & 5.312 & 4.419 & 4.031 & 3.722 \\
& {$[3.6-8.0]$} & {$[2.8-7.1]$} & {$[2.9-5.8]$} & {$[3.0-4.7]$} \\
\hline$\rho^{2}$ & 0.077 & 0.110 & 0.136 & 0.149 \\
\hline
\end{tabular}

(a) Calculated using the methodology presented in Ortúzar and Armstrong (1995)

Table 6: Discrete choice logit model results 